\title{
Experimental Hookworm Infection in Laboratory animals: Parasite behavior, Immune response and Chemotherapeutic Studies
}

Mahendra K. Bhopale

Department of Microbiology, R.D. Gardi Medical College, Ujjain, MP 456001, India.

Corresponding author: Mahendra K. Bhopale, Ph.D., D. Sc, Department of Microbiology \& Director (Research), R.D. Gardi Medical College, Ujjain, MP 456001, India.

Received date: April 27, 2021; Accepted date: May 31, 2021; Published date: June 15, 2021

Citation: Mahendra K. Bhopale, (2021) Experimental Hookworm Infection in Laboratory animals: Parasite behavior, Immune response and Chemotherapeutic Studies. J, Biotechnology and Bioprocessing, 2(5); DOI: 10.31579/2766-2314/040

Copyright: (C) 2021, Mahendra K. Bhopale, This is an open access article distributed under the Creative Commons Attribution License, which permits unrestricted use, distribution, and reproduction in any medium, provided the original work is properly cited.

\begin{abstract}
Hookworm disease is known to be caused allergic manifestation and severe anemic pathogenicity in man and canine hosts. Attempts have been made to establish laboratory models of Necator americaus, Ancylostoma duodenale, and Ancylostoma ceylanicum, together with canine parasite, Ancylostoma caninum. The studies include pathophysiological aspects of the host-parasite relationship, and develop to establish patent infection. Immunological approach to selecting antigen for diagnosis and protective immunity purpose using larval and adult worm antigens and their secretions became the focus with the subsequent discovery of cloning in vaccine development as main research interest. Chemotherapy of newer drug screening in laboratory models ultimately selected to use for preventive chemotherapy in hookworm endemic areas using recommended drugs.

Keywords: hookworms; laboratory model; hookworm antigens; protective immunity; anti-hookworm drugs; chemotherapy
\end{abstract}

\section{Introduction}

The incidence of intestinal helminthiasis, especially hookworm disease is alarmingly high in tropical and sub-tropical countries [1, 2]. Hookworm disease is known to be caused allergic manifestation and severe anemic pathogenicity commonly occurs in man and canine hosts. Research develops to study in parasite behavior, immunological and chemotherapeutic studies associated with hookworm infection predominantly in suitable models. The first idea for the development of a suitable animal model of human hookworm infection is the ability for the human parasite to develop normally in a laboratory animal. Second, the course of such infection and clinical manifestation produced by these parasites should resemble those seen in infected humans. Attempts have been made earlier to establish hookworm models by infecting a variety of laboratory animals to develop a complete life cycle, namely, Necator americaus, Ancylostoma duodenale, and in canine Ancylostoma ceylanucum. Dog hookworm, Ancylostoma caninum, accidentally infects humans known as zoonosis, wherein they migrate under the skin and remain in the larval stage in the host. Usually these cause an aberrant infection, "creeping eruption" or cutaneous larva migrans.

The established laboratory models of hookworm were used for the study of immunological and pathophysiological aspects of host-parasite relationship and the chemotherapeutical evaluation of newer drugs. All hookworm parasite antigens do not participate in protective immunity. The isolation and identification of antigens which elicit a protective immune response was studied for the full analysis. Research interest in hookworm disease was progressing further using molecular and immunology approach to develop a suitable vaccine [3, 4]. At the same time, search of newer drugs was continued screening in the laboratory animals and finally at the human trials [5].

\section{Parasite behavior}

Ancylostoma caninum: The pattern of infection with A. cainum in mice and rats is very similar in both species, but depends on the route of larval entry. Following oral inoculation more than $50 \%$ of the larvae penetrate intestinal tissue those which fail to pass out with host faeces. Successful larvae pass through the mucosa, probably through the liver, and by 17 hours can be recovered from the lungs [6]. Within 24 hours, larvae can be observed passing up the trachea, through the larynx and eventually localizing in the laryngeal and pharyngeal muscles. Three to four days post infection the maturity the majority sites only a few migrating further afield and, recovered $30 \%$ of the inoculated larvae from the muscles of the head, neck and thorax, in comparison to $3 \%$ from the hind limbs. When rodents are exposed to percutaneous (PC) or sub-cutaneous (SC) infection, the larvae migrate directly into the muscles throughout the body [7]. During the distribution phase some 
pass through the lungs, but there is no accumulation in the lungs as in orally-infected animals. Muscle larvae in rodents are essentially exsheathed third-stage larvae (L3). They show neither morphological change, nor development over the infective larvae while in the host. Viability is retained for a very long time depending on the intensity of initial exposure. The migration of $A$. duodenale is again very similar. The majorities of larvae localize in the somatic musculature irrespective of the route of inoculation, but survive for a limited period of 66 days.

Ancylostoma ceylanicum: A. ceylanicum succeeded in adapting this canine species to regular passage through hamsters, the larvae moulted to L4 by the second or third day and grew rapidly to moult again to preadult stage in 7-10 days. Parasite eggs appeared in hamster faeces 14-17 days after infection and peak egg production was usually apparent by 21-28 days [8]. A. ceylanicum appears to behave quite differently in mice than $A$. caninum found intestinal worms mouting to the L4 stage by day 3 , persisting for longer than a week. However, when cortisone was used worm burdens remained high for about three weeks, and the fertile parasites containing eggs were recovered on day 18 , coinciding with the first appearance of eggs in mouse faeces [9].

Necator americanus: The complex life cycle of the hookworm has opportunities for the host-parasite interaction during the larvae invade through the skin and transit through lung tissues to the gut mucosa diverse immune modulation. Necator americanus established hamster strain is capable to survive without cortisone [10]. However, it was observed normal development and achieves patent infections when hamsters were exposed to infective larvae within a week old pup [11]. By regular passage, it was possible to improve the adaptation of this strain to the hamster host [12]. Though $N$. americanus is susceptible to the infection in adult hamsters also, but the worms are rejected from the intestine soon after completing their migration from the lungs. $N$. americanus mature in hamsters, but only when 1 to 3 -day-old pups infected with larvae. However, older animals acquire resistance quickly and do not develop patent infections. Attempts have been made to use neonatal (two-day-old) rabbits to $N$. americanus with regular passage the pre-patent period was reduced and faecal egg counts rose to 40000 e.p.g. and worms persisted for up to 200 days [13]. Attempts were also made successfully the development of $A$. duodenale in neonatal rabbits when infected larvae orally (buccal pouch) and attained the adult stages to patent infection [14].

\section{Immune response}

Immune response to Ancylostoma caninum infection: Studies have been shown that repeated doses of the A. caninum larvae develop immunity in the mice. This study brings to alterations in serum proteins as a single dose or repeated doses following inoculation of A. caninum per os in mice with 250, 500, 1000, 2000, and 4000 infective larvae and $\beta$ globulin specifically was significantly elevated. However, a significant reduction in the $\gamma$-globulin was seen in these animals except in the groups which received $4000 \mathrm{~A}$. caninum larvae in mice [15]. Study on $A$ caninum in mice has also provided information on the role of cellmediated immunity when passively transferred sensitized peritoneal exudate cells [16], small and large intestinal mesenteric lymph node cells [17], and thymus and bone marrow cells separately [18, 19]. The activated immune cells transferred results show diminishing survival of migrating larvae in the tissue and due to the cause of earlier expulsion from the intestines with A. caninumin infection in mice [20]. Migratory larvae also destroyed in the muscles after allergic immobilized death due to the delayed type hypersensitivity response [21].
Immune response to Ancylostoma ceylanicum infection: Although A. ceylanicum has been transmitted experimentally to hamsters [8, 22], but no study on immune response to measure the humoral response to a primary infection until the study made to show positive reaction employing by agar diffusion, counterimmunoelectrophoresis (CIEP) and indirect haemaglutinating (IHA) tests for 20-60 days whereas CIEP until the 150 days of infection using sonicated soluble adult worm antigens [23]. They further measured similar parameters of IHA antibodies and the CIEP reaction in hamsters infected with $A$. ceylanicum treated with mebendazole [24].

Immune response to Necator americanus infection: $N$. americanus surface antigens of adult and L4 recognize serum antibodies and capable of immunoprecipitating on surface antigens recognized by excretorysecretory products during the infection of human and hamster postinfection $[25,26]$. Acquired resistance was monitored using the hamsteradapted strain of $N$. americanus infection in BALB/c mice by worm recovery and immunological assays after exposure to primary or secondary infections [27]. Soluble antigens from a third-stage (L3), adult homogenate, and excretory/secretory (ES) were used in various tests to examine humoral responses to N. americanus in infant rabbit model. Sera from rabbits infected with $N$. americanus duration the period of of 40-84 days were analyzed positive by CIEP against L3 larval antigen and also showed a significant attenuation in the albumin/globulin ratio in infected animals when compared to controls [13]. Antigen expression during the development of Necator americanus L3, L4 and adult is recognized by immunoblotting and immunoprecipitation analysis in natural host man, and the experimental hamster host [28]. There are correlations antibody responses between Necator americanus stage-specific antigens and parasite burden in an endemically-infected population in Papua New Guinea. Parasite burden declined significantly with age from positive in younger to significantly negative in older infected hosts. The presence of a positive correlation between eosinophil concentration and the infection intensity in adults indicates that eosinophilia reflects the host's worm burden, whereas levels of anti-ES antibodies dependent on worm burden. A trend of similar patterns was present for anti-larval-IgG in both pretreatment and after re-infected for anti-ES-IgM and anti-ES-IgE pretreatment [29]. In vitro experiments to assess the skin penetration by ensheathed thirdstage infective larvae (L3) of Necator americanus visually observed using a novel fluorescein isothiocyanate (FITC)-labeling technique [30]. Studies also emphasized on experimental approaches to develop a recombinant hookworm genetically engineered vaccine in controlling this infection in highly endemic areas. Recombinant polypeptide belonging to the Ancylostoma secreted protein (ASP)-1 family has shown promising results of reducing hookworm burdens after larval challenge infection in mice [31].

Irradiated larval vaccine: Earlier, a highly effective vaccine was developed to control A. caninum infection in dogs immunized with $\mathrm{X}$ irradiated A. caninum L3, protected against subsequent challenge with normal larvae [32]. This immunity could be transferred passively to naive recipients by serum and lymphoid cells [33], but not cleared whether larvae were killed during migration or adults were expelled from the gut due to the effect of vaccination. With UV-irradiated $A$. ceylanicum larvae stimulated resistance in hamsters. A high level of protection afforded by larvae irradiated for $15 \mathrm{~min}$ UV-exposure was recorded giving $99.0 \%$ and $95.0 \%$ worm reduction against the challenge doses of 100 and 1000 normal larvae respectively. There was no marked difference in worm establishment in hamsters vaccinated either orally or 
subcutaneously, followed by oral challenge A. ceylanicum infection in hamsters. In the vaccinated hamsters, the manifestations of resistance at 15 min UV-exposure was shown by marked reduction in worm establishment and highly reduced epg in pellets, and a significantly higher blood hemoglobin levels compared with those given normal larvae as vaccine and challenge controls. [34].

A preliminary study illustrated that active immunization of $A$. ceylanicum (Ac) whole worm (ww) and larval somatic (som) and excretory-secretory (es) antigen separately in hamsters, gave 93.22\% (Ac-ww-som-Ag), 100\% (Ac-ww-es-Ag), 92.70\% (Ac-larval-som-Ag) and $95.83 \%$ (Ac-larval-es-Ag) worm protection respectively against the normal challenge dose. Further, Ac-ww-som-Ag separated through Sephadex G- 200 column gave $96.2 \%$ worm protection when immunized with fraction-F2 as compared to -F1 (88.62\%) and - F3 $(72.51 \%)$ against the challenge normal dose. Passive immunization of immune serum HHIS (Hyper immunized raise in hamsters) by inoculated UV- irradiated larvae (x3), showed (85\% to 90\%) worm protection against the normal challenge infection. Immunoglobulin (IgG) separated from the pooled serum samples of HHIS-IgG (Hamster Hyper Immunized Serum-IgG) and RHIS-IgG (Rabbit Hyper Immunized Serum-IgG), showed $97.67 \%$ and $92.20 \%$ worm reduction respectively against the normal challenge dose.

Parasite antigen selection and cloning: Ancylostoma-secreted-protein applied in cloning and characterization of a novel protein, ASP-1 [35]. Vaccination of mice with either third-stage Ancylostoma caninum infective hookworm larvae (L3) or alum-precipitated recombinant Ancylostoma secreted protein 1 (Ac-ASP-1) results in protection against hookworm challenge infections. Passive immunization with pooled sera from recombinant Ac-ASP-1-vaccinated mice also resulted in lung hookworm burden reductions in the muscles and also elevated IgG1 and IgG2b in the host [36]. Mice were immunized with recombinant ASPs from different hookworm species which showed different degrees of protection depends on amino acid sequence homology [37]. AceES-2 (Cloning of Ancylostoma ceylanicum-excretory-secretory-protein-2), a novel protein produced by adult worms plays an important role in the host-parasite interaction and represent a useful strategy for controlling hookworm infection [38]. Aspartyl protease inhibitors (API-1) from parasitic nematodes are highly immunogenic, and have been suggested as potential vaccine antigens. API-1 was cloned and characterized from the hookworms, A. caninum and A. ceylanicum. The highly immunogenic properties of nematode aspins suggest that Ac-API-1 represents a promising target for a recombinant hookworm vaccine [39]. Ad-III-ESA (anti-A. duodenale immunoglobulin (Ig) G4 antibody fraction III of the partially purified excretory secretary antigen of adult worm was studied. The level of serum specific IgG4 was measured by indirect enzyme linked immunosorbent assay and compared with serum specific IgG, IgG-1, -2 and -3 subclass antibodies [40]. Two classes of fatty acid and retinol binding proteins produce by nematodes. A partial cDNA was cloned from a polyprotein antigen/ allergen (NPA) to the NPA (AccNPA) which correspond to four subunits of putative $A$. ceylanicum. The amino acid sequence of AceNPA shares sequence identity with similar proteins from Dictyocaulus viviparos, Ascaris suum and Ostertagia ostertagi [41]. Another study on Necator americanusAncylostoma-Secreted-Protein-2 (Na-ASP-2) binds an ascaroide (ascr\#3) in its fatty acid binding site has been progressed for the search of small molecules found in E-S products of hookworms include nematode derived metabolites of ascarosides, which are composed of the sugar ascarylose linked to a fatty acid side chain [42].

\section{Chemotherapy}

Many reports have attempted screening of anti-hookworm drugs in the laboratory models against the adult stage of hookworm of human and canine origin. Selected drugs were screened where mebendazole was the most effective, with parbendazole, phenylene 1,4-diisothiocyanate, thiabendazole and bephenium hydroxynaphthoate also satisfactory [43]. The compound, 3, 5-dibromo-2'-chloro-4'-isothiocyanatosalicylanilide, has been tested against various nematode and cestode parasites in experimental and domestic animals. It showed $100 \%$ activity against $A$. ceylanicum, A. tubaeformis [44]. The anthelmintic activity of Amoscanate (C 9333-GO/CGP 4540) has been studied in Necator americanus infection in hamsters with single oral doses of $30-60 \mathrm{mg} / \mathrm{kg}$ eliminated 94 to $99 \%$ parasites in 37-day-old non-patent infection, while single oral doses of $25 \mathrm{mg} / \mathrm{kg}$ expelled the entire worm burden in patent infection [45]. Necator americanus in infant rabbit system mebendazole appeared to be $100 \%$ effective at $100 \mathrm{mg} / \mathrm{kg}$ at single dose clear all worms [46]. The efficacy of eight ant-helmintics against Ancylostoma caninum larvae in the skeletal muscles of mice was evaluated using levamisole $(5 \times 40 \mathrm{mg} / \mathrm{kg})$, thiabendazole $(5 \times 400 \mathrm{mg} / \mathrm{kg})$, oxfendazole (5 X $100 \mathrm{mg} / \mathrm{kg}$ ), albendazole (5 X $100 \mathrm{mg} / \mathrm{kg}$ ), flubendazole (5 X 200 $\mathrm{mg} / \mathrm{kg}$ ), benacil (5 X $200 \mathrm{mg} / \mathrm{kg}$ ) and phenacizole (5 X $200 \mathrm{mg} / \mathrm{kg}$ ) showed marked larvicidal activity (98 to 99\%) whereas Sch 18099 did not show larvicidal activity even at 5 X $400 \mathrm{mg} / \mathrm{kg}$ [47]. The benzimidazole derivatives viz. thiabendazole, oxibendazole, parbendazole, and fenbendazole showed marked activity only at high dosage rates in A. caninum infection in Mastomys natalensis system [48]. However, none is reported whether the drug is capable of eliminating all the developmental stages of hookworms.

In a preliminary study of $A$. ceylanicum in golden hamsters, the efficacy of of mebendazole, albendazole, parbendazole, flubendazole and ivermectin was evaluated at the stage $3^{\text {rd stage, }}($ day 1$), 4^{\text {th stage }}$, (day 4$) 5^{\text {th }}$ stage (day 7) and adult stage (day 12), and necropsies were made on the day 20 for the adult worm recovery prior withhold of food one day before. Among those drugs, albendazole showed $100 \%$ efficacy at the dose of $50 \mathrm{mg} / \mathrm{kg}$ against the L3 and the L4 stages; $10 \mathrm{mg} / \mathrm{kg}$ against the L5 stage; and $5 \mathrm{mg} / \mathrm{kg}$ against the adult stage. So also another drug, ivermictin showed $100 \%$ efficacy at the dose of $0.005 \mathrm{mg} / \mathrm{kg}$ against the L3 stage; $0.003 \mathrm{mg} / \mathrm{kg}$ against the L4 stage; $0.002 \mathrm{mg} / \mathrm{kg}$ against the L5 stage; and $0.005 \mathrm{mg} / \mathrm{kg}$ against the adult stage. This study suggests that albendazole and ivermictin clear all the developmental parasitic stages, including the adults of $A$. ceylanicum infection in hamsters.

Soil-transmitted helminthiasis (STHs) affects almost 2 billion people worldwide in tropical climates. Such helminths (hookworms, Ascaris lumbricoides, and Trichuris trichiura) in highly endemic areas were used in preventive chemotherapy to control with available drugs. The efficacy of single oral dose of albendazole, mebendazole, and pyrantel pamoate against hookworm infections was $72 \%$ in 742 patients; $15 \%$ in 853 patients; and $31 \%$ in 152 patients respectively [5]. This drug trial study provided robust results on the efficacy and safety of coadministration of ivermectin and albendazole to WHO recommendations for control of soil-transmitted helminthiasis, and provides the extended effects of combination therapy [49].

\section{Conclusion}

Human and canine hookworm models established in laboratory animals representing $N$. americanus, $A$. ceylanicum and $A$. caninum infection to study parasite behavior, immune response and chemotherapeutical evaluation of newer drugs. Protective immune response was observed in the host on repeated larval infections and passive transferring sensitized 
immune cells in A. caninum infection in mice. Protective immunity induced by UV- irradiated larvae, somatic and excretory-secretory antigen and passive transfer of $\mathrm{IgG}$ in hamsters against the challenge of A. ceylanicum infection have been observed. Progress in advance research using molecular and immunological techniques were made in cloning of Ancylostoma ceylanicum excretory-secretory protein 2 (AceES-2), Ac-API-1 clone represents a promising target for a recombinant hookworm vaccine. The anti- $A$. duodenale serum derived immunoglobulin (Ig) -G4 fraction III of partially purified excretory secretary antigen of adult worm (Ad III ESA), and Necator americanusAncylostoma Secreted Protein-2 (Na-ASP-2) were achieved showing promising results. Among those drugs screened in laboratory animal models of $N$. americanus; A. ceylanucum and A. caninum against adults or larvae hookworms, but ivermictin and albendazole were found promising drugs to clear all the parasitic developmental stages of $A$. ceylanucum infection in hamsters.

\section{Acknowledgements}

Gratefully acknowledged to Dr. V. K. Mahadik, Director, R. D. Gardi Medical College for the encouragements and to establish and develop research in biomedical sciences.

\section{References}

1. Hotez PJ, Brooker S, Bethony JM, Bottazzi ME, Loukas A and Xiao S (2004) Hookworm infection. $N$ Engl J Med; 351:799-807.

2. Hotez PJ, Hawdon JM, Cappello M, Jones, BF, Ghosh K, Volvovitz, F and Xiao SH (1996) Molecular approaches to vaccinating against hookworm disease. Pediatr Res 40: 515-521.

3. Hotez PJ, Hawdon JM, Cappello M, Jones, BF, Ghosh K, Volvovitz, F and Xiao SH (1996) Molecular approaches to vaccinating against hookworm disease. Pediatr Res 40: 515521.

4. Weatherhead JE, Gazzinelli-Guimaraes P, Knight JM, Fujiwara R, Hotez PJ, Bottazzi ME and Corry DB (2020) Host Immunity and Inflammation to Pulmonary Helminth Infections. Front Immunol; 11:594520.

5. Keiser J and Utzinger J (2008) Efficacy of current drugs against soil-transmitted helminth infections: systematic review and meta-analysis. JAMA; 299: 1937-1948.

6. Bhopale MK and Johri GN (1975) Experimental infection of Ancylostoma caninum in mice. II. Migration and distribution of larvae in tissues after oral infection. J Helminthol; 49:179-185

7. Banerjee D, Prakash O and Deo MG. (1970) Studies on Ancylostoma caninum infection in mice following percutaneous and intraperitoneal routes of infection. Indian $J$ Med Res; 58:1313-1320.

8. Ray DK and Bhopale KK (1972) Complete development of ancylostoma ceylanicum (Looss, 1911) in golden hamsters, mesocricetus auratus. Experientia; 28:359-361.

9. Ray DK, Bhopale KK and Shrivastava VB (1975) Development of Ancylostoma ceylanicum Looss, 1911 (hamster strain) in the albino mouse, Mus musculus, with and without cortisone. Parasitology; 71:193-197.

10. Sen HG and Seth D (1967) Complete development of the human hookworm, Necator americanus in golden hamsters, Mesocricetus auratus. Nature; 214: 609-610.

11. Sen HG and Seth D (1970) Development of Necator americanus in golden hamsters Mesocricetus auratus. Indian $J$ Med Res; 58:1356-1360.

12. Sen HG (1972) Necator americanus behaviour in hamsters. Exp Parasitol; 32: 26-32.
13. Bhopale M K, Menon S and Kulkarni L (1980) Necator americanus in infant rabbits: complete development, humoral antibody, leukocyte response and serum protein changes following infection. J Helminthol; 54: 97-104.

14. Bhopale M K and Menon S (1979) Complete development of human hookworm, Ancylostoma duodenale (Dubini, 1843) in infant rabbits. Experientia; 35:463-464.

15. Bhopale MK and Johri GN (1978) Experimental infection with Ancylostoma caninum larvae in mice. V. Serum protein pattern during infection with various doses. J Hyg Epidemiol Microbiol Immunol; 22:319-327.

16. Vardhani VV and Johri GN (1983) Transfer of delayed hypersensitivity through repeatedly sensitized peritoneal exudate cells during experimental ancylostomiasis in mice. Folia Parasitol (Praha); 30:147-151.

17. Vyas S, Vardhani VV and Johri GN (1981) Ancylostoma caninum: immunization through transfer of sensitized lymphoid cells \& their effect on the expulsion and/or destruction of worm burden in Swiss albino mice. Indian J Exp Biol; 19:752-753.

18. Kolhe NP, Lakshmi PN and Johri GN (1979) Studies on experimental ancylostomiasis: transfer of acquired immunity to Ancylostoma caninum in mice through sensitized thymus and bone marrow cells. Experientia; 35: 1242-1243.

19. Lakshmi PN, Kolhe NP and Johri GN (1982) Ancylostoma caninum: immune response to and distribution pattern of larvae in mice with sensitized thymus and bone marrow cells. J Hyg Epidemiol Microbiol Immuno; 26:300-307.

20. Vardhani VV and Johri GN (1979) Intestinal mast cells during experimental ancylostomiasis. J Helminthol; 53:35-39.

21. Vardhani VV and Johri GN (1981) Delayed (cellular) hypersensitivity in mice during experimental ancylostomiasis. III. Effect of longer latent period for immobilisation of challenged larvae in the adoptively immunized host. $J$ Hyg Epidemiol Microbiol Immunol; 25:150-154.

22. Ray DK, Bhopale KK and Shrivastava VB (1972) Migration and growth of Ancylostoma ceylanicum in golden hamsters Mesocricetus auratus. J Helminthol; 46:357-362

23. Menon S and Bhopale MK (1985) Ancylostoma ceylanicum (Looss, 1911) in golden hamsters (Mesocricetus auratus): pathogenicity and humoral immune response to a primary infection. J Helminthol; 59:143-146.

24. Kamath VR, Bhopale MK and Bhide MB (1985) Immunological evidence of chemotherapeutic action of mebendazole against Ancylostoma ceylanicum (Looss, 1911) in hamsters (Mesocricetus auratus). J Helminthol; 59:195-199.

25. Pritchard DI, Behnke JM, Carr A and Wells C (1986) The recognition of antigens on the surface of adult and L4 Necator americanus by human and hamster post-infection sera. Parasite Immunol; 8:359-367.

26. Carr A and Pritchard DI (1986) Identification of hookworm (Necator americanus) antigens and their translation in vitro. Mol Biochem Parasitol; 19:251-258.

27. Wells C and Behnke JM (1988) Acquired resistance to the human hookworm Necator americanus in mice. Parasite Immunol; 10:493-505.

28. Carr A and Pritchard DI (1987) Antigen expression during development of the human hookworm, Necator americanus (Nematoda). Parasite Immunol; 9:219-234.

29. Pritchard DI, Quinnell RJ, Slater AF, McKean PG, Dale DD, Raiko A and Keymer AE (1990) Epidemiology and immunology of Necator americanus infection in a community in Papua New Guinea: humoral responses to excretorysecretory and cuticular collagen antigens. Parasitology; 100:317-326. 
30. Kumar S and Pritchard DI (1992) Skin penetration by ensheathed third-stage infective larvae of Necator americanus, and the host's immune response to larval antigens. Int $J$ Parasitol; 22:573-579.

31. Hotez PJ, Ghosh K, Hawdon JM, Narasimhan S, Jones B, et al. (1999) Experimental approaches to the development of a recombinant hookworm vaccine. Immunol Rev; 171:163-171.

32. Miller TA (1965) Persistence of immunity following double vaccination of pups with $\mathrm{x}$-irradiated Ancylostoma caninum larvae. J Parasitol; 51:705-711.

33. Miller TA (1967) Transfer of immunity to Ancylostoma caninum infection in pups by serum and lymphoid cells. Immunology; 12:231-241.

34. Menon S and Bhopale MK (1985) Efficacy of UV-irradiated larval vaccine of Ancylostoma ceylanicum (Looss, 1911) in golden hamsters (Mesocricetus auratus). J Helminthol; 59:287293.

35. Hawdon JM, Jones BF, Hoffman DR and Hotez PJ (1996) Cloning and characterization of Ancylostoma-secreted protein. A novel protein associated with the transition to parasitism by infective hookworm larvae. J Biol Chem.; 271:6672-6678.

36. Ghosh K and Hotez PJ (1999) Antibody-dependent reductions in mouse hookworm burden after vaccination with Ancylostoma caninum secreted protein 1. J Infect Dis; 180:1674-1681

37. Sen L, Ghosh K, Bin Z, Qiang S, Thompson MG, Hawdon JM, Koski RA, Shuhua X and Hotez PJ (2000) Hookworm burden reductions in $\mathrm{BALB} / \mathrm{c}$ mice vaccinated with recombinant Ancylostoma secreted proteins (ASPs) Ancylostoma duodanale, Ancylostoma caninum and Necator americanus. Vaccine; 18:1096-1102

38. Bungiro RD Jr, Solis CV, Harrison LM and Cappello M (2004) Purification and molecular cloning of and immunization with Ancylostoma ceylanicum excretory-secretory protein 2, an immunoreactive protein produced by adult hookworms. Infect Immun; 72:2203-2213.

39. Delaney A, Williamson A, Brand A, Ashcom J, Varghese G, Goud GN and Hawdon JM (2005) Cloning and characterisation of an aspartyl protease inhibitor (API-1) from Ancylostoma hookworms. Int J Parasitol; 35:303-313.
40. Mahmoud MS, Abou Gamra MM and Elkhayat MM (2005) Ancylostoma duodenale infection: a study of serum immunoglobulin G4 response to the excretory secretory antigen of adult worm. J Egypt Soc Parasitol; 35:1-17.

41. Fairfax KC, Harrison LM and Cappello M (2014) Molecular cloning and characterization of a nematode polyprotein antigen/allergen from the human and animal hookworm Ancylostom ceylanicum. Mol Biochem Parasitol; 198:37-44.

42. El Atab O, Darwiche R, Truax NJ, Schneiter R, Hull KG, Romo D and Asojo OA (2020) Necator americanus Ancylostoma Secreted Protein-2 (Na-ASP-2) Binds an Ascaroside (ascr\#3) in Its Fatty Acid Binding Site. Front Chem; 8:608296.

43. Ray DK, Bhopale KK and Shrivastava, VB (1978) Efficacy of seven anthelmintics against Ancylostoma ceylanicum in the golden hamster, Mesocricetus auratus. Ann Trop Med Parasitol; 72: $56-58$

44. Katiyar JC, Visen PK, Gupata S, Sen AB, Dubey SK and Sharma S (1982) 3, 5-Dibromo-2'-chloro4'isothiocyanatosalicylanilide, a potent anthelmintic. Experientia; 38:457-460.

45. Sen HG and Deb BN (1981) Anthelmintic efficacy of amoscanate (C 9333-Go/CGP 4540) against various infections in rodents, dogs and monkeys. Am J Trop Med Hyg; 30:992998

46. Bhopale MK, Menon S and Kamath VR (1982) The anthelmintic effects of mebendazole on Necator americanus in rabbit model. J Helminthol; 56:355-356.

47. Bhopale GM and Bhatnagar BS (1985) The efficacy of some newer broad spectrum anthelmintics against third-stage larvae of Ancylostoma caninum in the mouse. J Helminthol; 59:307311.

48. Lämmler G and El-Gendi AY (1978) The efficacy of anthelmintics against third stage larvae of Ancylostoma caninum in Mastomys natalensis. Parasitenkd; 58: 55-63.

49. Patel C, Hürlimann E, Keller L, Hattendorf J, Sayasone S, Ali SM, Ame SM , Coulibaly JT and Keiser J (2019) Efficacy and safety of ivermectin and albendazole co-administration in school-aged children and adults infected with Trichuris trichiura: study protocol for a multi-country randomized controlled double-blind trial. BMC Infect Dis; 19:262.

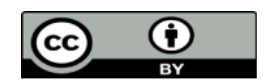

This work is licensed under Creative Commons Attribution 4.0 License
Ready to submit your research? Choose Auctores and benefit from:

* fast, convenient online submission

* rigorous peer review by experienced research in your field

* rapid publication on acceptance

* authors retain copyrights

* unique DOI for all articles

* immediate, unrestricted online access

At Auctores, research is always in progress.

Learn more www.auctoresonline.org/journals/biotechnology-andbioprocessing 